\title{
Second-Trimester Diagnosis of Triploidy: A Series of Four Cases
}

\author{
J. B. Wick ${ }^{1}$ \\ K. J. Johnson, MS, $\mathrm{CGC}^{2}$ J. O'Brien, $\mathrm{MD}^{3}$ \\ ${ }^{1}$ St. John's University, Collegeville, Minnesota \\ ${ }^{2}$ Department of Medical Genetics, Mayo Clinic, Rochester, Minnesota \\ 3 Division of Maternal Fetal Medicine, Department of Obstetrics and \\ Gynecology, Mayo Clinic, Rochester, Minnesota \\ ${ }^{4}$ Department of Obstetrics and Gynecology, Mayo Clinic, Rochester, \\ Minnesota \\ ${ }^{5}$ Department of Medical Genetics, Mayo Clinic, Rochester, Minnesota
}

M. J. Wick, MD, $\mathrm{PhD}^{4,5}$

\author{
Address for correspondence Myra J. Wick, MD, PhD, Eisenberg 4-A, \\ Mayo Clinic, 200 First St SW, Rochester MN, 55905 \\ (e-mail: wick.myra@mayo.edu).
}

Am J Perinatol Rep 2013;3:37-40.

\begin{abstract}
Keywords

- triploidy

- ultrasound

- phenotype

- second trimester

Triploidy occurs in 2 to $3 \%$ of conceptuses and accounts for approximately $20 \%$ of chromosomally abnormal first-trimester miscarriages. As such, triploidy is estimated to occur in 1 of 3,500 pregnancies at 12 weeks', 1 in 30,000 at 16 weeks', and 1 in 250,000 at 20 weeks' gestation. We present a series of four cases of second-trimester triploidy diagnosed at our center within a 1-year timeframe. This is remarkable, as the delivery volume at our institution is roughly 2,500/y. All patients were at least 19 weeks' gestation, with multiple abnormalities identified on prenatal ultrasound at 18 to 20 weeks' gestation; all fetuses had lethal anomalies, but anomalies were not consistent between cases. All patients elected for induction of labor before 24 weeks' gestational age. Two of the four cases had amniocentesis and chromosome analysis prior to delivery, and two cases had chromosome analysis performed on fetal tissue after delivery. All fetuses were examined following delivery. This case series demonstrates that the diagnosis of triploidy may not be obvious based on ultrasound and physical examination findings and highlights the importance of routine chromosome analysis on all prenatal diagnoses of multiple congenital anomalies prior to consideration of more complex genetic testing.
\end{abstract}

Triploidy occurs in about 2 to $3 \%$ of conceptuses, resulting from an extra haploid chromosome set, either paternal (diandric) or maternal (digynic) in origin. ${ }^{1,2}$ The majority of diandric triploids result from simultaneous fertilization by two sperm. Other triploidies of diandric origin arise from normal fertilization of the ovum by a diploid sperm, the result of complete nondisjunction during spermatogenesis. Triploidies of digynic origin result from fertilization of a primary oocyte or from fertilization of a diploid oocyte that is a product of nondisjunction during meiosis I, meiosis II, or retention of a polar body. ${ }^{3}$

Nearly all triploid pregnancies (>99\%) are spontaneously aborted during the first trimester. ${ }^{4}$ The low frequency of

received

July 7, 2012

accepted after revision

July 31, 2012

published online

December 31, 2012 triploidy among advanced pregnancies has led to discrepancies in prevalence estimates, ranging from as low as 1 in 250,000 at 20 weeks ${ }^{5}$ to as high as 1 in 50,000 among liveborn infants. ${ }^{6,7}$ Nevertheless, second- and third-trimester triploidy are rare events. Recently, four cases of secondtrimester triploidy were diagnosed at our tertiary center within a 1-year period. This is unusual, given an annual delivery volume of approximately 2,500 births and a referral base (Mayo Health System, Olmsted Medical Center) of around 6,300 deliveries annually. Here we report ultrasound (US) findings, cytogenetic analyses, and clinical characteristics for this case series and compare clinical characteristics of these cases to features reported in the literature.
Copyright (c) 2013 by Thieme Medical Publishers, Inc., 333 Seventh Avenue, New York, NY 10001, USA. Tel: +1(212) 584-4662.
DOI http://dx.doi.org/ 10.1055/s-0032-1331378. ISSN 2157-6998. 


\section{Case Reports}

For cases 1,2 , and 3, gestational age was determined by firsttrimester US; dating was determined by 14 -week US for case 4 .

\section{Case 1}

The first patient, a 19-year-old gravida 1 with a spontaneous pregnancy, was referred to our institution at $20^{4 / 7}$ weeks' gestation for anomalies detected on anatomy US. Upon referral, an advanced-level US with amniocentesis was performed. US findings included intrauterine growth restriction, duodenal atresia, and cardiac malformations (-Fig. 1). Chromosomal analysis revealed a 69,XXY karyotype. The patient underwent elective induction of labor at $21^{1 / 7}$ weeks and delivered a stillborn infant. The growth-restricted fetus had male genitalia and exhibited normocephaly with microretrognathia and low-set ears. Physical exam of the chest and back was unremarkable; however, 3,4 syndactyly of the right hand and foot were noted (-Fig. 2). The placenta had a threevessel cord, exhibited no hydropic changes, and was below the 10 th percentile for weight.

\section{Case 2}

A 30-year-old G2P1001 woman with a spontaneous pregnancy was referred to our institution at $22^{0 / 7}$ weeks' gestation for multiple anomalies detected on routine anatomy US. Advanced-level US findings included intrauterine growth restriction, Dandy Walker variant, and possible asphyxiating thoracic dystrophy. The patient elected to have an induction of labor due to poor prognosis, and subsequently delivered a stillborn infant. Cytogenetic study revealed a 69,XXX karyotype. Upon physical exam, the fetus exhibited normal female genitalia and growth restriction. Relative macrocephaly with facial asymmetry and low-set ears were noted. The fetus had a widened sternum and short rib cage. Malformations of the extremities included 3,4 syndactyly of the left hand, 4,5 syndactyly of the right foot, and equinovarus ( $\mathbf{F i g . ~ 3 A , ~ B ) . ~}$ The placenta had a three-vessel cord and showed no hydropic changes. Placental weight was below the tenth percentile.

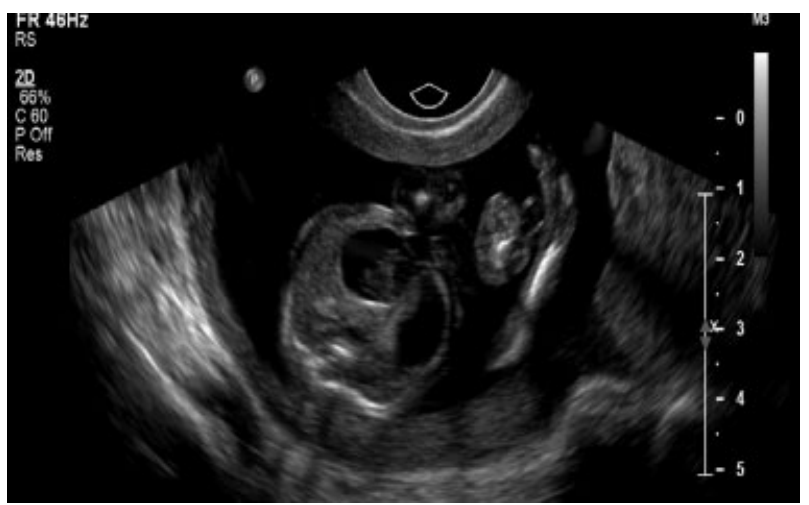

Fig. 1 Transverse view of the fetal abdomen in case 1, demonstrating the classic "double bubble" sign consistent with duodenal atresia. The two cystic structures represent an enlarged fluid-filled stomach and proximal duodenum. The pylorus between the stomach and duodenum is also dilated and visible.

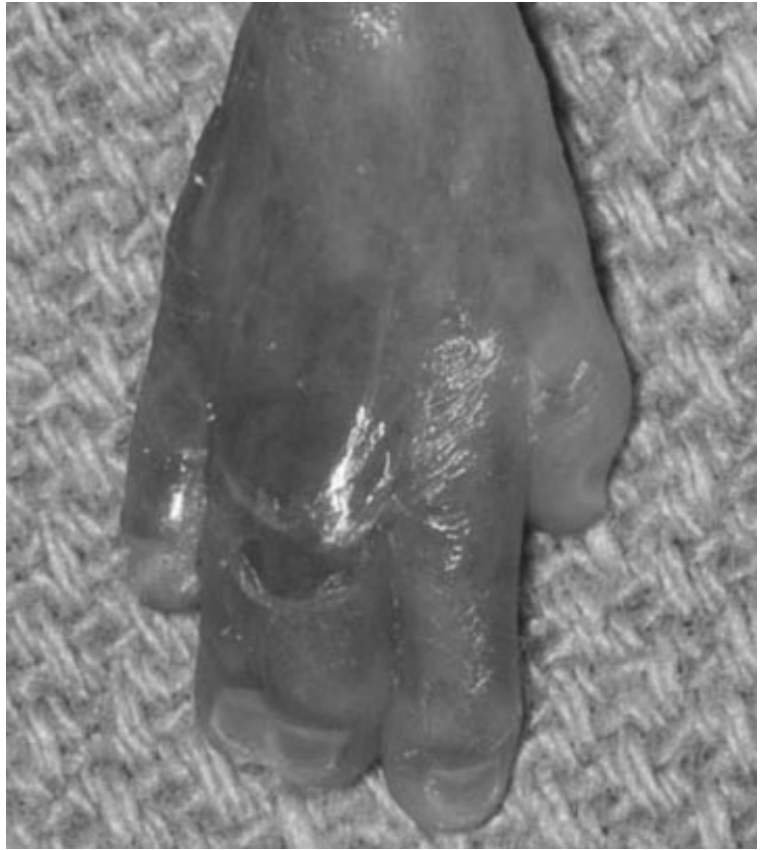

Fig. 2 Physical exam of fetus in case 1 revealed 3,4 syndactyly of the right hand.

\section{Case 3}

The third patient was a 27-year-old G2P1 woman with a spontaneous pregnancy referred to our institution at $19^{2 / 7}$ weeks' gestation after anatomy US revealed severe intrauterine growth restriction. Pregnancy complications included firstand second-trimester bleeding, a psychiatric disorder, and a poor social situation. After advanced-level US revealed intrauterine growth restriction, ventriculomegaly, atrial and ventricular septal defects, and diaphragmatic hernia, the patient was counseled regarding prognosis, and labor was induced. She delivered a stillborn infant. Growth restriction and normal female genitalia were noted upon physical examination. The fetus exhibited relative normocephaly with a tall forehead, microretrognathia, and low-set ears. Physical examination of the chest and back was remarkable for shortened sternal length and splayed ribs. Malformations of the extremities included 2,3 syndactyly of the left hand and 4,5 syndactyly of the right foot. The placenta had a three-vessel cord and showed no hydropic changes. Placental weight was below the 10th percentile. Skin and placenta samples were sent to the cytogenetics laboratory. The laboratory was unable to establish cell culture for chromosome analysis; however, fluorescence in situ hybridization analysis revealed three copies of chromosomes $13,15,16,18,21,22$, and X, consistent with triploidy.

\section{Case 4}

The fourth patient was a 29-year-old G2P1 woman with a spontaneous pregnancy and followed in our routine prenatal clinic. Anatomy US at $18^{1 / 7}$ weeks revealed multiple fetal anomalies. Advanced-level US revealed a two-vessel cord, ventriculomegaly, and a Dandy Walker variant. Amniocentesis and subsequent chromosome analysis demonstrated a 69, XXX karyotype (-Fig. 4), and the patient elected for induction of labor at $19^{4 / 7}$ weeks. She delivered a stillborn fetus. 


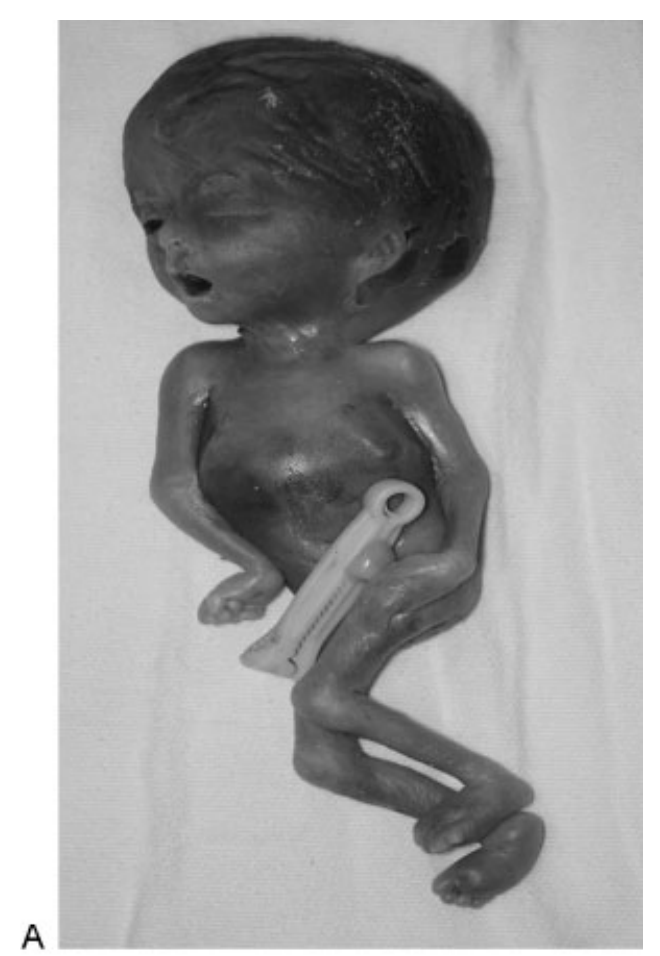

A

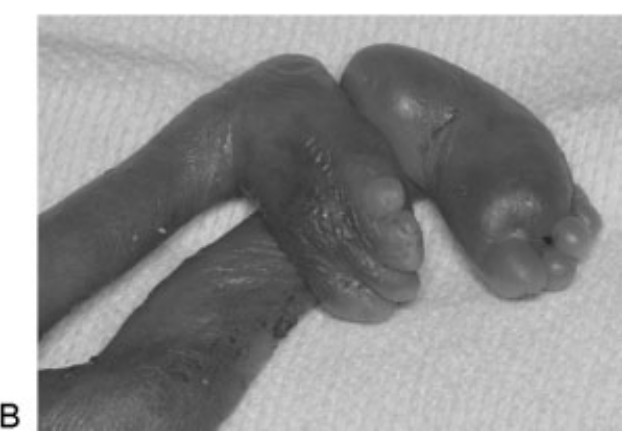

Fig. 3 The fetus in case 2, demonstrating growth restriction, relative macrocephaly with facial asymmetry, and low-set ears. The sternal length is shortened, and ribs are splayed (A). Malformations of the lower extremities in case 2 included 4,5 syndactyly of the right foot and equinovarus (B).

Physical exam showed normal growth and female genitalia. Relative normocephaly with microretrognathia and low-set ears was noted. Physical exam of the chest and back was unremarkable; however, the extremities exhibited webbing between the first and second and second and third toes. The placenta had a two-vessel cord and exhibited hydropic changes consistent with partial mole. Placental weight was below the 10th percentile.

\section{Discussion}

All triploidy cases in this series were detected by identification of multiple anomalies on routine anatomy US at 18 to 20 weeks' gestation. Although anomalies varied between cases, each of the fetuses had significant US findings, resulting in elective induction of labor in the second trimester. All fetuses and placentas were examined after delivery. US, clinical features, and placental findings from each of the cases are summarized in - Table $\mathbf{1}$.

\section{Ke Mill M M}

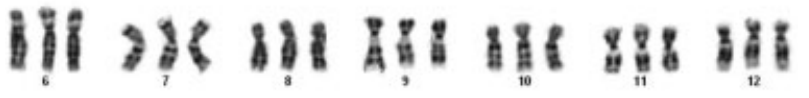

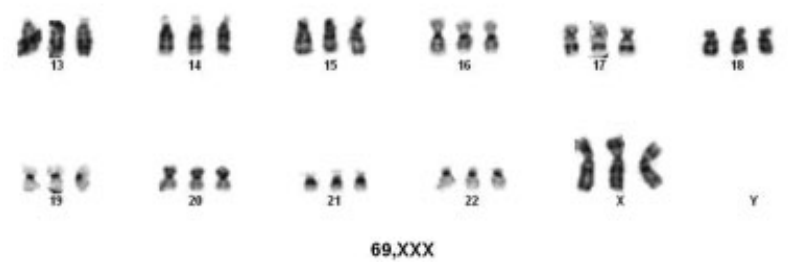

Fig. 4 Chromosomal analysis in case 4 revealed a 69,XXX karyotype.

Specific phenotypic characteristics have been previously reported to correspond with the parental origin of the extra chromosome set. McFadden and Kalousek ${ }^{6}$ defined the diandric phenotype as "type 1 ," in which the pregnancy features a normally sized or slightly growth restricted fetus with normal adrenal glands and typically has a large, cystic placenta with characteristics of partial hydatidiform mole. The "type 2" phenotype, which is of digynic origin, exhibits severe asymmetric intrauterine growth restriction, relative macrocephaly, adrenal hypoplasia, and a small, noncystic placenta. ${ }^{1,2}$ Although definitive determination of parental origin may be of academic interest, it does not necessarily provide information regarding clinical management or outcomes and requires parental samples to undergo expensive molecular-based analysis. Other abnormalities in triploid pregnancy that are not specific to the parent of origin include 3,4 syndactyly of fingers and toes; congenital defects of the genitourinary, cardiac, renal, and neurological systems; abnormal development of the lungs; and dysmorphic facial features. ${ }^{8}$ This case series demonstrates that the diagnosis of triploidy, irrespective of parental origin, may not be obvious based on US findings and physical examination findings.

Formal examination of the placental may also be useful in formulating differential diagnosis and can provide clues regarding parental origin of the triploidy. All cases in this series exhibited placental abnormalities, with one case also exhibiting umbilical cord abnormalities. All placentas had poor growth, with placental weights below the 10th percentile. Small, noncystic placentas have been associated with digynic triploidy, and diandric triploidy is associated with placentas that are abnormally large and cystic, consistent with features of partial hydatidiform mole. ${ }^{1,6,8}$ Interestingly, the placenta from case 4 exhibited characteristics of both diandric and digynic triploidy, as it was small with hydropic changes and dysmorphic villi consistent with partial hydatidiform mole. Nevertheless, case 4 illustrates the importance of placental evaluation for patient management in triploid pregnancy, as patients with pathological evidence of partial hydatidiform mole should be monitored for gestational trophoblastic disease. 
Table 1 Ultrasound, clinical, and placental findings from cases 1-4

\begin{tabular}{|c|c|c|c|c|}
\hline & Case 1 & Case 2 & Case 3 & Case 4 \\
\hline Patient age $(\mathrm{y})$ & 19 & 30 & 27 & 29 \\
\hline Gestational age (wk) & $20^{4 / 7}$ & $22^{0 / 7}$ & $19^{2 / 7}$ & $18^{1 / 7}$ \\
\hline Pregnancy history & G1 & G2P1001 & G2P1001 & G2P1001 \\
\hline Reason for referral & Abnormal anatomy US & Abnormal anatomy US & Abnormal anatomy US & Abnormal anatomy US \\
\hline Level II US findings & $\begin{array}{l}\text { IUGR, duodenal atre- } \\
\text { sia, cardiac } \\
\text { malformations }\end{array}$ & $\begin{array}{l}\text { IUGR, possible } \\
\text { asphyxiating thoracic } \\
\text { dysplasia, Dandy } \\
\text { Walker variant }\end{array}$ & $\begin{array}{l}\text { IUGR, } \\
\text { ventriculomegaly, } \\
\text { atrial and } \\
\text { ventricular septal } \\
\text { defects, } \\
\text { diaphragmatic hernia }\end{array}$ & $\begin{array}{l}\text { Two-vessel cord, } \\
\text { ventriculomegaly, } \\
\text { Dandy Walker variant }\end{array}$ \\
\hline $\begin{array}{l}\text { Physical exam: overall } \\
\text { growth }\end{array}$ & Growth restriction & Growth restriction & Growth restriction & Normal growth \\
\hline Physical exam: HEENT & $\begin{array}{l}\text { Normocephaly, } \\
\text { microretrognathia, } \\
\text { low-set ears }\end{array}$ & $\begin{array}{l}\text { Relative macrocephaly } \\
\text { with facial asymmetry, } \\
\text { low-set ears }\end{array}$ & $\begin{array}{l}\text { Relatively normoce- } \\
\text { phalic with tall fore- } \\
\text { head, microretrogna- } \\
\text { thia, low-set ears }\end{array}$ & $\begin{array}{l}\text { Relative } \\
\text { normocephaly, } \\
\text { micrognathia, low-set } \\
\text { ears }\end{array}$ \\
\hline $\begin{array}{l}\text { Physical exam: chest, } \\
\text { back }\end{array}$ & Unremarkable & $\begin{array}{l}\text { Widened sternum with } \\
\text { short rib cage }\end{array}$ & $\begin{array}{l}\text { Shortened sternal } \\
\text { length splayed ribs }\end{array}$ & Unremarkable \\
\hline Physical exam: genitalia & Male & Female & Female & Female \\
\hline $\begin{array}{l}\text { Physical exam: } \\
\text { extremities }\end{array}$ & $\begin{array}{l}3,4 \text { syndactyly of right } \\
\text { hand and foot }\end{array}$ & $\begin{array}{l}3,4 \text { syndactyly of left } \\
\text { hand, } 4,5 \text { syndactyly of } \\
\text { right foot, equinovarus }\end{array}$ & $\begin{array}{l}2,3 \text { syndactyly of left } \\
\text { hand, } 4,5 \text { syndactyly of } \\
\text { right foot }\end{array}$ & $\begin{array}{l}\text { Webbing between 1st } \\
\text { and 2nd, 2nd and 3rd } \\
\text { toes }\end{array}$ \\
\hline Placenta & $\begin{array}{l}\text { Weight }<10 \text { th } \\
\text { percentile, 3-vessel } \\
\text { cord, no hydropic } \\
\text { changes }\end{array}$ & $\begin{array}{l}\text { Weight }<10 \text { th } \\
\text { percentile, 3-vessel } \\
\text { cord, no hydropic } \\
\text { changes }\end{array}$ & $\begin{array}{l}\text { Weight <10th percen- } \\
\text { tile, 3-vessel cord, no } \\
\text { hydropic changes }\end{array}$ & $\begin{array}{l}\text { Weight }<10 \text { th } \\
\text { percentile, 2-vessel } \\
\text { cord, hydropic } \\
\text { changes consistent } \\
\text { with partial mole }\end{array}$ \\
\hline Chromosome analysis & $69, X X Y$ & $69, X X X$ & $\begin{array}{l}\text { FISH consistent with } \\
69, \mathrm{XXX}\end{array}$ & $69, X X X$ \\
\hline Presumed phenotype & Digynic & Digynic & Digynic & Diandric \\
\hline
\end{tabular}

Abbreviations: FISH, fluorescence in situ hybridization; HEENT, head, eyes, ears, nose, throat; IUGR, intrauterine growth restriction; US, ultrasound.

The presentation of four cases of second-trimester triploidy at our institution within 1 year highlights the importance of including triploidy in the differential diagnosis for cases where multiple fetal anomalies are identified on US. In addition, this case series illustrates the utility of routine chromosome analysis as a diagnostic tool for cases of multiple congenital anomalies, as newer technologies such as array comparative genomic hybridization and cell-free fetal DNA testing may not accurately detect triploidy. ${ }^{9,10}$

\section{References}

1 McFadden DE, Langlois S. Parental and meiotic origin of triploidy in the embryonic and fetal periods. Clin Genet 2000; 58:192-200

2 McFadden DE, Kwong LC, Yam IY, Langlois S. Parental origin of triploidy in human fetuses: evidence for genomic imprinting. Hum Genet 1993;92:465-469
3 Baumer A, Balmer D, Binkert F, Schinzel A. Parental origin and mechanisms of formation of triploidy: a study of 25 cases. Eur J Hum Genet 2000;8:911-917

4 Gardner RJM, Sutherland GR, Schaffer LG. Chromosome Abnormalities and Genetic Counseling. 4th ed. New York, NY: Oxford University Press; 2012

5 Daniel A, Wu Z, Bennetts B, et al. Karyotype, phenotype and parental origin in 19 cases of triploidy. Prenat Diagn 2001;21: 1034-1048

6 McFadden DE, Kalousek DK. Two different phenotypes of fetuses with chromosomal triploidy: correlation with parental origin of the extra haploid set. Am J Med Genet 1991;38:535-538

7 Doshi N, Surti U, Szulman AE. Morphologic anomalies in triploid liveborn fetuses. Hum Pathol 1983;14:716-723

8 McFadden DE, Robinson WP. Phenotype of triploid embryos. J Med Genet 2006;43:609-612

9 Lapaire O, Lu XY, Johnson KL, et al. Array-CGH analysis of cell-free fetal DNA in $10 \mathrm{~mL}$ of amniotic fluid supernatant. Prenat Diagn 2007;27:616-621

10 Chiu RW, Lo YM. Noninvasive prenatal diagnosis empowered by high-throughput sequencing. Prenat Diagn 2012;32:401-406 